\title{
Classification of Local Pepper Collections (Capsicum spp.) from Eritrea Using Morphological Traits
}

\author{
Brhan Khiar Saleh ${ }^{1,2}$, Remmy W. Kasili², Edward G. Mamati³, Woldeamlak Araia1, \\ Aggrey B. Nyende ${ }^{2}$ \\ ${ }^{1}$ Hamelmalo Agricultural College, Keren, Eritrea \\ ${ }^{2}$ Institute for Biotechnology Research, Jomo Kenyatta University of Agriculture and Technology, Nairobi, Kenya \\ ${ }^{3}$ Department of Horticulture, Jomo Kenyatta University of Agriculture and Technology, Nairobi, Kenya \\ Email: brhan200220@yahoo.co.uk
}

Received 10 February 2016; accepted 20 March 2016; published 24 March 2016

Copyright (C) 2016 by authors and Scientific Research Publishing Inc.

This work is licensed under the Creative Commons Attribution International License (CC BY).

http://creativecommons.org/licenses/by/4.0/

(c) (i) Open Access

\section{Abstract}

Diversity studies are an essential step in plant breeding and understanding the genetic relationships between pepper accessions may provide an effective management tool for their conservation, as well as help inform plant breeding efforts. The objective of the study was to assess the diversity and structure of pepper germplasm grown in Eritrean to help inform improvement programs. Local pepper (Capsicum spp.) germplasm collected from farmers and institutions in Eritrea was assessed using 16 quantitative morphological traits. The evaluation was conducted in two sites using a Randomized Complete Block Design with three replications. The data from the two sites were subjected to Principal Component Analysis, Hierarchal clustering with Euclidean distance and Analysis of variance. Cluster analysis of the combined data grouped the 60 genotypes into five clusters and 10 sub-clusters confirming the diversity of the collection that can be useful for selection and source of desired genes. A selection index was used to identify at least four promising genotypes (HD0134, HD0031 and NRSG21 and NRSAF06) for dry consumption purposes. The results of the current study revealed the relatively high level diversity existed within the evaluated collections and partitioned them into meaningful groups.

\section{Keywords}

Cluster Analysis, Genetic Diversity, Eritrean Pepper, Morphological Traits 


\section{Introduction}

Pepper occupies an essential position in the Eritrean diet. It is consumed in a variety of forms ranging from fresh consumption to various dry powder forms. It is produced all over the country in a range of small holding subsistence farming to medium sized commercial entities. Its importance varies from being part of the cropping system for subsistence farmers in the highlands, which is the dominant and only source of income for major production areas in Eritrea such as the Damas and Afabet [1]. During the sixties and seventies of the previous century, the country used to export pepper to outside markets. However, in the last decade production and productivity are declining. Several factors are affecting productivity, which includes unavailability of improved seed which is among the most important constraints. This situation makes it necessary to have a sound breeding program in order to provide farmers with varieties that have high productivity, acceptable quality, well adapted to local conditions and satisfy consumer preferences.

The genus Capsicum to which pepper belongs consists 31 species of which five are domesticated [2]. The genetic diversity exists within the various domesticated species of Capsicum and has been very little exploited and certainly not yet been exhausted [3]. This diversity includes a wide range of fruit forms and color [4], however, among the cultivated species $C$. annuum enjoys the highest morphometric diversity, and is cultivated almost all over the world [5]. The diversity available in the domesticated Capsicum should be easy to utilise compared to the problems associated with interspecific gene transfer [3]. Diversity studies are an essential step and pre-requisite in plant breeding and could produce valuable knowledge for crop improvement programmes [6] [7]. Genetic diversity studies are also useful for conservation, evaluation and utilization of genetic resources and for determining the uniqueness and distinctness of genotypes [8]. Understanding the genetic relationships between pepper accessions may provide an effective management tool for their conservation, as well as help inform plant breeding efforts [9]. Several methods have been used in diversity studies of the genus Capsicum. Assessment of genetic diversity of crop plants is a common practice. Methods used for assessment are morphological characterization, biochemical characterization and molecular marker analysis [10]. Hierarchical cluster analysis is a useful tool for partitioning variability of collections for managing them effectively and provides ground for curators and breeders to enhance the usefulness of their collections [11].

The wide range of distribution of peppers has created an opportunity for local germplasm leading to varieties and landraces to exist. Landraces are important genetic resources because they have unique gene pools and serve as important reservoirs of genetic diversity for breeding and conserving biodiversity [12]. The use of morphological characterization for studying genetic diversity of local pepper germplasm, including landraces, accessions and cultivated varieties, has long been used for identifying the potential for breeding to meet desirable traits. Many scientists around the world have studied variability in germplasm and have clustered them into genetically related groups for selecting superior genotypes for using them in future breeding and crop improvement programs [13]-[17]. Usually farmers in Eritrea save their own seed and transfer it from generation to the next. However, proper seed production methods, including isolation techniques, are not in practice within and among farms, giving the chance to out-cross and introgression forces to take place. In addition to that seed exchange across the border with Ethiopia was active for a long time and from the Italian colonial period (1889-1941) many exotic varieties were introduced. This is the reason as to why local pepper sold in the market is of mixed pods, containing a wide range of fruit size, color, pungency, etc., reflecting the rich genetic variation, existing in the local genotypes. However, the magnitude of this diversity has not yet evaluated. Thus the objective of this study was to assess the diversity and structure of pepper germplasm grown in Eritrean to help inform improvement programs.

\section{Materials and Methods}

A total of 60 seed sample collections collected from farmers and institutions was used in this study (Figure 1). These are 52 from farmers, six breeding lines from Hamelmalo Agricultural College and two breeding lines from the National Agricultural Research Institute. The 52 samples collected from farmers are not named varieties or landraces, but a kind of heirloom saved by farmers and transferred from generation to the next and exchanged among farmers within the village or beyond. Thus, they are denoted here as farmer varieties or collections. The seeds were sown in nursery beds and transplanted into $1 \mathrm{~m}$ wide and $3.4 \mathrm{~m}$ long beds with inter and intra row spacing of $50 \mathrm{~cm}$ in two locations. The testing locations were Hamelmalo Agricultural College, located at $15^{\circ} 52^{\prime} 35^{\prime \prime} \mathrm{N}$ and $38^{\circ} 27^{\prime} 45^{\prime \prime} \mathrm{E}$ with an elevation of $1264 \mathrm{~m}$ above sea level and Asmara (Halibet) located at $15^{\circ} 18^{\prime} 42^{\prime \prime} \mathrm{N}$ and $38^{\circ} 56^{\prime} 15^{\prime \prime} \mathrm{E}$ with an elevation of $2335 \mathrm{~m}$ above sea level (Figure 1). Average annual rainfall 


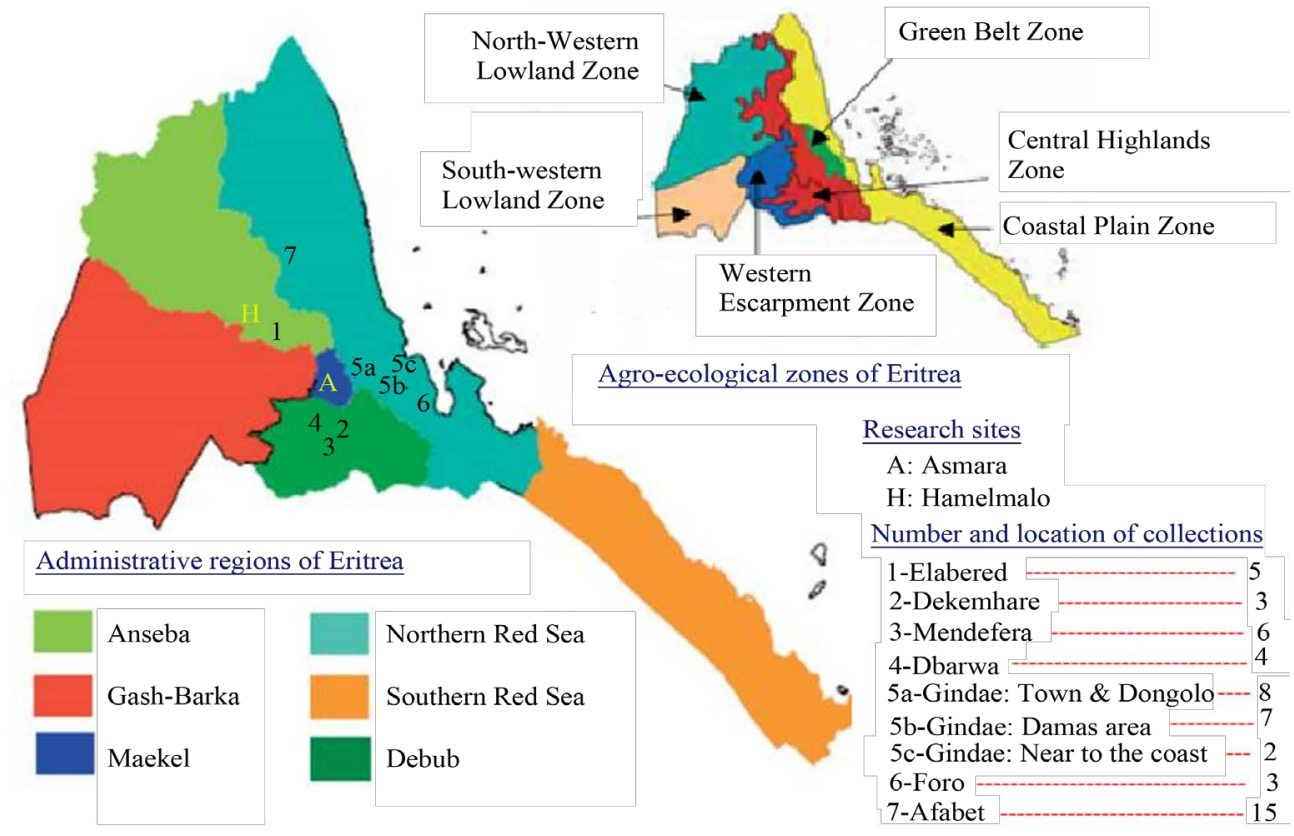

Figure 1. Map of Eritrea showing seed collection locations, number collections from each location and research sites in different administrative regions and agro-climatic region.

and temperature in Asmara for the period 2008-2013 was $408 \mathrm{~mm}$ and $8.8^{\circ} \mathrm{C}$, respectively, while in Hamelmalo the average for the period 2010-2012 was $415 \mathrm{~mm}$ and $21.7^{\circ} \mathrm{C}$. A Randomized Complete Block Design (RCBD) with three replications was used in each site.

A total of 16 quantitative morphological characters [18] were recorded. These were seedling, phenology, leaf and fruit characteristics. The data were analyzed using GENSTAT Discovery edition 4, version 10.3.0.0 (VSN International Ltd, 2011) and the data was subject to Principal component analysis (PCA), Hierarchal clustering with Euclidean distance and Analysis of variance. Hierarchical cluster analysis using data from the two sites separately and combined was conducted based on correlation similarity matrix for handling the different scales of measurements of the variables [19]. Euclidean test with complete link criteria was followed.

Ranking genotypes for dry consumption purpose was conducted using an index value of five calculated from the performance of genotypes on yield, earliness to fruit and three other yield and quality related fruit traits.

\section{Results}

\subsection{Classification of Collections}

Grouping of the collections was at $80 \%$ similarity coefficient and sub-clustering at $90 \%$ when data of the two sites used separately. Based on the aforementioned coefficients the 60 genotypes tested at Hamelmalo were grouped into four main clusters and those tested in Asmara were grouped into three main clusters.

At Hamelmalo site both clusters I and III included 18 genotypes, cluster II contained 23 genotypes, while cluster IV was formed with a single genotype (HD0134) (Figure 2). The main feature of cluster I was, 50\% of genotypes were from Gindae. The cluster was sub-clustered into three. Sub-cluster A was composed of four genotypes from Gindae, each two from Foro and Afabet and one for Elabered. Sub-cluster B was composed of four clusters from Gindae and three from Mendefera, while sub-cluster $C$ formed of two genotypes, one each from Gindae NRSG09) and Afabet (NRSAF14) (Figure 2).

Cluster II was composed of 23 genotypes and no further sub-clustered into four. The main feature of this cluster is except NARI all seed sources were represented. Sub-cluster D included two genotypes from Dubarwa and each one from Elabered, Mendefera, Dbarwa and Gindae. Sub-cluster E was formed of each two from Elabered, Dbarwa and HAC and each one from Foro and Dekemhare. Five genotypes from Gindae and each one from Elabered and Mendefera were inferred to Sub-cluster F. The last sub-cluster (G) included two genotypes, 


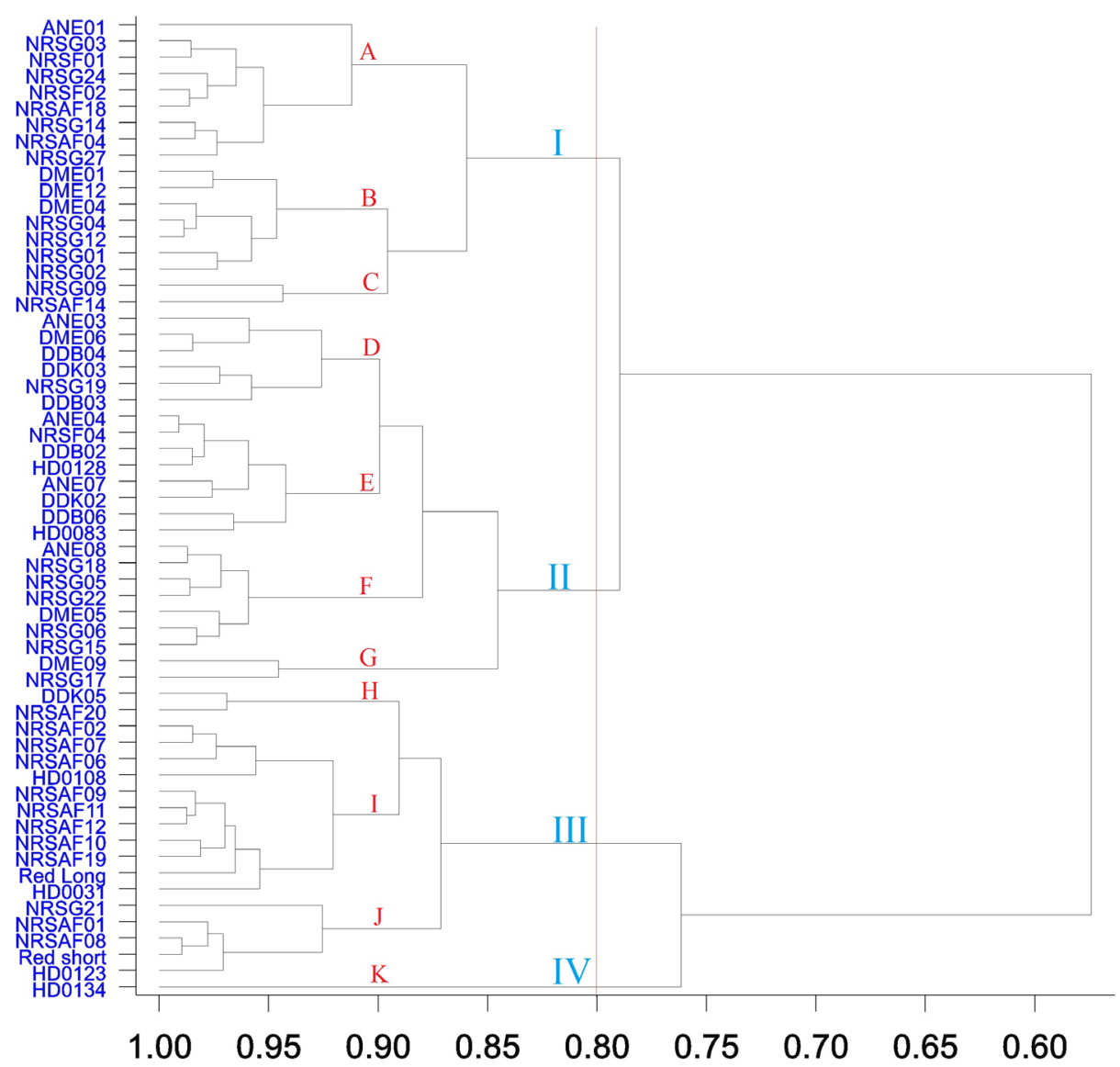

Figure 2. Dendrogram generated by hierarchical cluster analysis showing the relationships among the 60 pepper genotypes at Hamelmalo using 16 quantitative characteristics.

each one from Gindae (NRSG17) and Mendefera (DME09) (Figure 2).

A total of 18 genotypes were inferred to cluster III of which 11 were from Afabet. The cluster was sub-divided into three sub-clusters. Sub-cluster $\mathrm{H}$ was the smallest and included each one from Dekemhare (DDK05) and Afabet (NRSAF20). Sub-cluster I was the largest and included eight genotypes from Afabet, two from HAC and one from NARI. The last sub-cluster ( $\mathrm{J}$ ) was formed of two genotypes from Afabet and each one from HAC, NARI and Gindae (Figure 2).

The structure of the dendrogram generated using data from Asmara site was similar to that of Hamelmalo. Number of genotypes inferred into clusters I and III was 17 and 16 respectively, while in cluster II the number was larger (27) (Figure 3). Cluster I was composed of three sub-clusters (A, B and C). Sub-cluster "A" included two genotypes each from Elabered and Afabet and one genotype each from Gindae and Dekemhare. Sub-cluster "B" was composed of nine genotypes six of them from Gindae, two from Foro and one each Elabered and Mendefera, while sub-cluster C included only one genotype each from Gindae and Dubarwa (Figure 3).

Cluster II with 27 genotypes was the largest and grouped into four sub-clusters (D, E, F and G). The major feature of this cluster is that all populations except those genotypes from NARI are represented; five out of six genotypes, from Mendefera and 10 out of 17 from Gindae genotypes are inferred to this cluster. Sub-cluster 'D' included three genotypes from Mendefera and one each from Elabered and Dubarwa. Sub-cluster "E" is composed of four genotypes from Gindae and one genotype each from Elabered, Mendefera and Dekemhare and Afabet. Sub-cluster "F" included two each from Dubarwa, Afabet and HAC and one from Mendefera. Subcluster "G" was composed of six genotypes from Gindae and one genotype from Mendefera (Figure 3).

Cluster III included genotypes DDK05 and HD0031 each solitary in sub-cluster "H" and sub-cluster "K", two genotypes each from Afabet and HAC in sub-cluster "I", and seven genotypes from Afabet, two from NARI and one from HAC in sub-cluster "J" (Figure 3). 


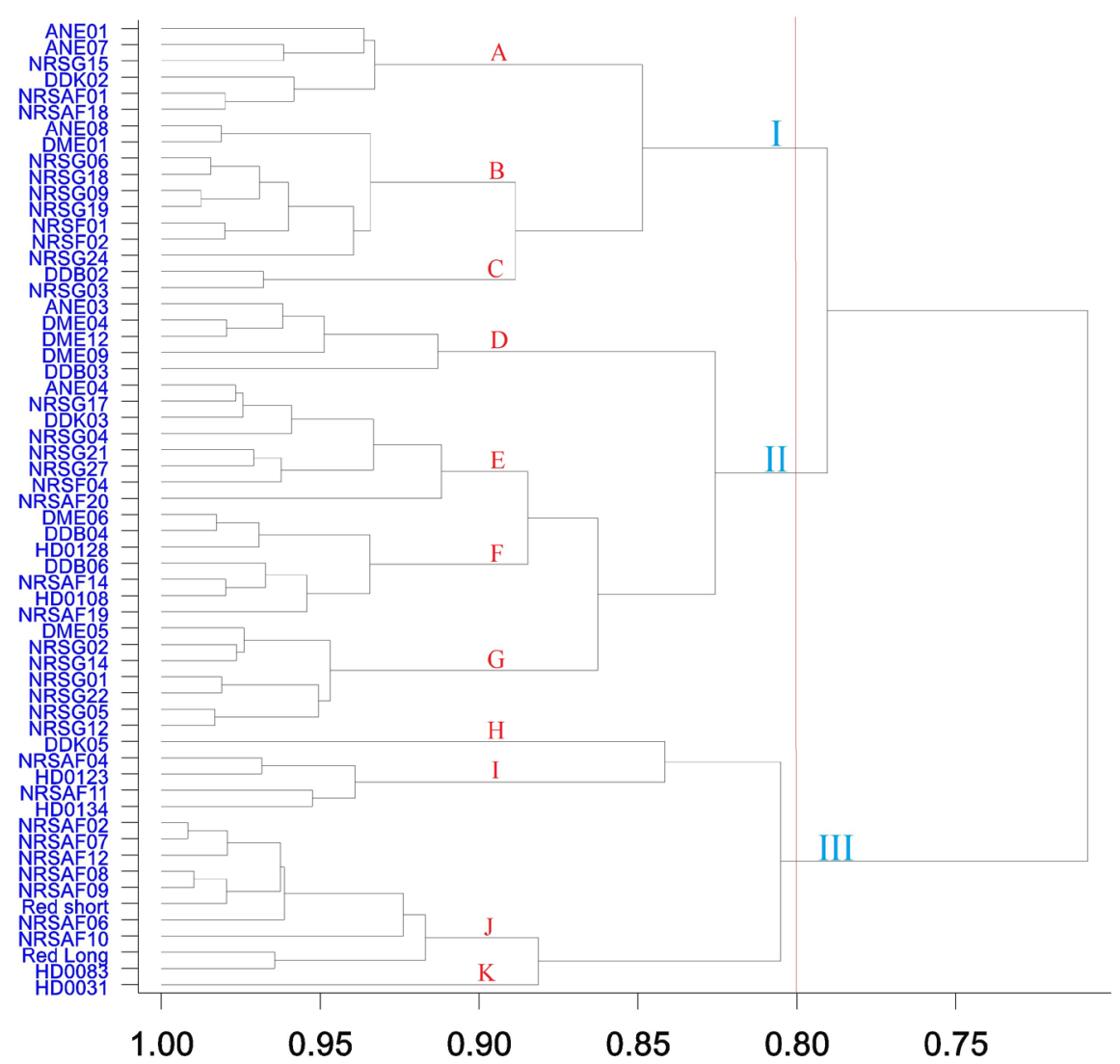

Figure 3. Dendrogram generated by hierarchical cluster analysis showing the relationships among the 60 pepper genotypes in Asmara using 16 quantitative characteristics.

Cluster analysis of the combined data from two sites: The cutoff on $85 \%$ similarity coefficient showed clearer structure of the 60 genotypes. They were grouped into five clusters (Figure 4). Cluster I was composed of three sub-clusters and included 20 genotypes. Sub-cluster "A" with nine genotypes was the largest and composed of three genotypes each from Elabered and Foro and tow genotypes from Afabet and one genotype from Dekemhare. Sub-cluster "B" was composed of six genotypes, three from Dubarwa and one genotype each from Elabered, Mendefera and HAC. The last sub-cluster in this group was sub-cluster " $\mathrm{C}$ " which included five genotypes one each from Dekemhare, Dubarwa and Mendefera in the Debub region in addition to one each from Afabet and HAC (Figure 4).

Cluster II was composed of 20 genotypes and divided into two sub-clusters (D \& E). The main feature of this cluster is that 14 out of the 20 members are from Gindae. Sub-cluster "D" included four genotypes from Gindae, two from Mendefera and one each from Elabered Foro and Afabet. In sub-cluster "E", all genotypes except one (DME12) are from Gindae. Cluster III is the smallest one and composed of only two genotypes (DME09 and NRSG17). Cluster IV included 12 genotypes grouped into two sub-clusters. Sub-cluster "G" was the smallest and composed of two genotypes, one each from Dekemhare (DDK05) and Afabet. Sub-cluster "H" was composed of 10 of which seven are from Afabet, two from NARI and one from HAC. This is in addition to two genotypes from NARI and one from HAC. The six genotypes in cluster V are, three from HAC, two from Afabet and one from Gindae.

\subsection{Analysis of Variation among Clusters}

The results of the analysis of variance conducted on the five groups resulted from the combined data of the two sites (Figure 4) showed that the groups were significantly different for all the 16 quantitative variables (Table 1). These results were consistent with the results of PC analysis (data not shown) that showed the contribution of each group to each of the five PCs. For example Groups IV and V showed higher mean values for yield and 


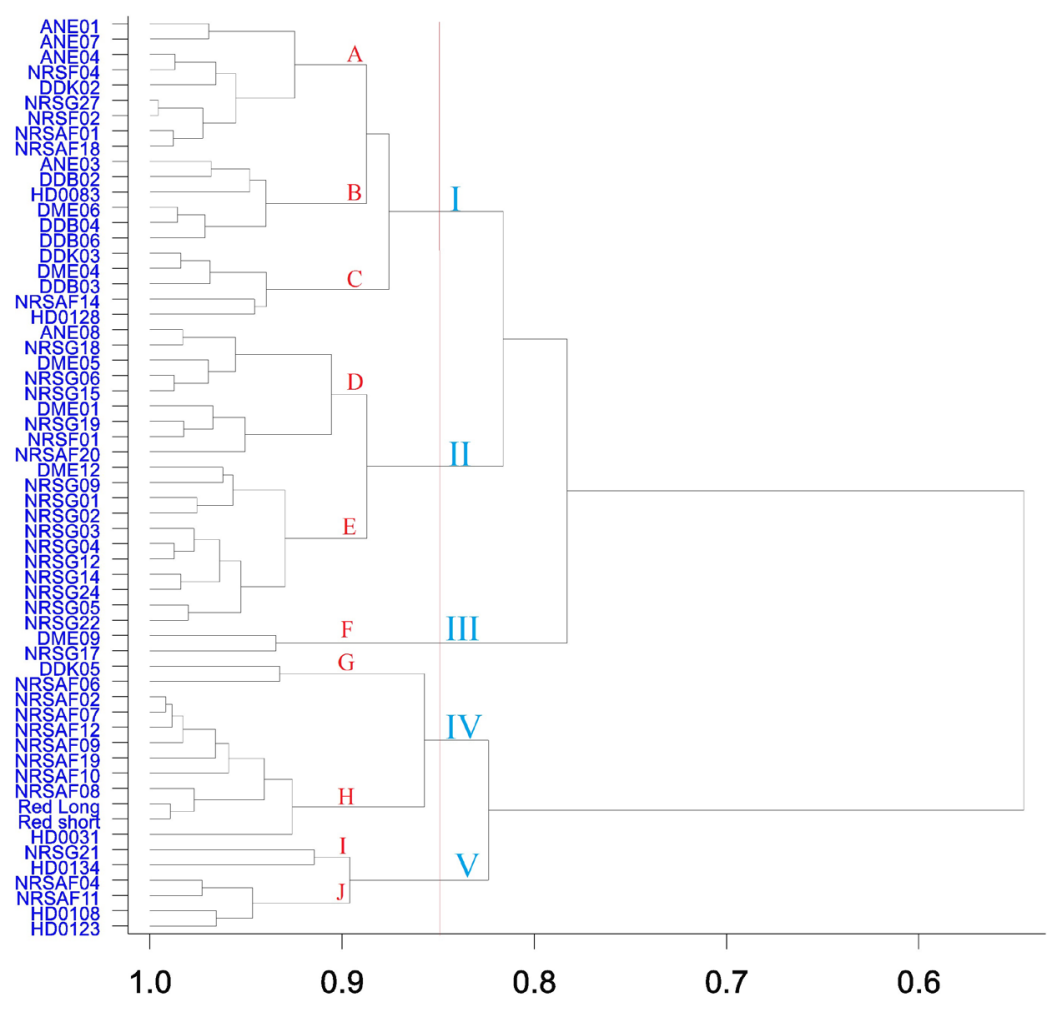

Figure 4. Dendrogram generated by hierarchical cluster analysis showing the relationships among the 60 pepper genotypes based on the combined data of the two sites using 16 quantitative characteristics.

Table 1. Mean performance of the five clusters of 16 quantitative traits based on the combined data of the two sites displayed in Figure 3.

\begin{tabular}{|c|c|c|c|c|c|c|c|c|}
\hline Cluster & DG & CLL & CLW & PHt & STh & LML & LMW & DFl \\
\hline I & 11.7 & 23.5 & 6.7 & 45.8 & 13.7 & 9.4 & 4.5 & 51.5 \\
\hline II & 11.3 & 22.8 & 6.5 & 47.1 & 13.7 & 8.8 & 4.0 & 53.7 \\
\hline III & 10.0 & 24.9 & 7.5 & 47.0 & 13.3 & 7.6 & 3.6 & 46.6 \\
\hline IV & 11.5 & 25.2 & 6.9 & 47.7 & 14.8 & 10.8 & 4.9 & 55.2 \\
\hline V & 12.5 & 24.5 & 6.5 & 51.8 & 15.4 & 11.2 & 5.2 & 53.6 \\
\hline Mean & 11.5 & 23.7 & 6.7 & 47.31 & 14.08 & 9.61 & 4.5 & 53.0 \\
\hline s.e. & 1.10 & 1.72 & 0.70 & 7.56 & 2.57 & 1.77 & 0.77 & 5.23 \\
\hline P-value & $<0.001$ & $<0.001$ & $<0.001$ & $<0.001$ & $<0.001$ & $<0.001$ & $<0.001$ & $<0.001$ \\
\hline CV (\%) & 9.6 & 7.2 & 10.5 & 16.0 & 18.3 & 18.4 & 17.4 & 9.9 \\
\hline Cluster & $\mathrm{DFr}$ & FL & FW & FWTh & FWt & TSS & $\mathrm{NFr} / \mathrm{P}$ & $\mathrm{Y} / \mathrm{Pl}$ \\
\hline I & 62.3 & 9.2 & 2.4 & 2.0 & 15.1 & 6.4 & 45.3 & 419.7 \\
\hline II & 64.9 & 10.2 & 1.7 & 1.7 & 10.6 & 6.3 & 62.6 & 393.5 \\
\hline III & 55.8 & 9.6 & 1.8 & 1.7 & 9.2 & 6.0 & 74.0 & 336.8 \\
\hline IV & 66.4 & 10.5 & 2.9 & 2.3 & 25.0 & 6.3 & 37.3 & 584.3 \\
\hline V & 66.1 & 10.2 & 3.1 & 2.2 & 26.4 & 7.3 & 43.1 & 743.8 \\
\hline Mean & 64.2 & 9.9 & 2.31 & 1.98 & 16.57 & 6.42 & 50.3 & 474.8 \\
\hline s.e. & 6.04 & 1.49 & 0.60 & 0.37 & 7.65 & 1.12 & 23.43 & 266.76 \\
\hline P-value & $<0.001$ & $<0.001$ & $<0.001$ & $<0.001$ & $<0.001$ & $<0.001$ & $<0.001$ & $<0.001$ \\
\hline CV (\%) & 9.4 & 15.0 & 26.0 & 18.7 & 46.2 & 17.4 & 46.6 & 56.2 \\
\hline
\end{tabular}

CLL = Cotyledon leaf length; CLW = Cotyledon leaf width; DFl = Days to flowering; FW = Fruit width; DFr = Days to fruiting; DG = Days to germination; FL = Fruit length; FWTh = Fruit wall thickness; FWt = Fruit weight $\mathrm{LML}=$ Leaf mature length; LMW = Leaf mature width; STh = Stem thickness; NFr/P = Number of fruits per plant; $\mathrm{PHt}=$ Plant height; TSS = Total soluble solids; $\mathrm{Y} / \mathrm{Pl}=\mathrm{Yield} / \mathrm{plant}$. 
yield related traits (Table 1). Genotypes inferred to the aforementioned two groups highly contributed to PC1 and PC2 which were related to yield and yield related traits.

\subsection{Evaluation of the Performance of the Collections}

The performance of the collections was evaluated based on yield and four fruit quality parameters suitable or dry consumption purpose. Based on a selection index value of five; the best 14 collections that scored a value of three and above are listed in Table 2. These included 5 from HAC, 7 from Afabet and each one from NARI and Gindae. The 14 collections were grouped into 6 ranks. The first in rank included two breeding lines (HD0134 and HD0031) and were characterized by medium fruiting, medium to long fruit, wide fruit, medium fruit wall thickness and yield ranging 861 to $1139 \mathrm{~g}$. The second in rank included one farmer variety (NRSG21) and characterized by medium fruiting, medium fruit length, wide fruit with medium fruit wall thickness and an average yield of $1110 \mathrm{~g}$. The third in rank included one farmer variety (NRSAF06) which was characterized by medium in days to fruiting, medium fruit length, wide fruit, medium fruit wall thickness and an average yield of $851 \mathrm{~g}$. The last three ranks included nine collections that had performance similar to the pervious three ranks, but lower average yield per plant that range 433 - $607 \mathrm{~g}$ as described in Table 2.

\section{Discussion}

Hierarchical cluster analysis is a useful tool for managing collections more effectively, partition their variability and give ground for curators and breeders to further enhance the usefulness of their collections [11]. In the current study cluster analysis using 16 quantitative traits showed at $82 \%$ similarity coefficient 60 genotypes tested in Asmara grouped into three major clusters and at $87 \%$ the genotypes formed 11 sub-clusters (Figure 3). However, when the same genotypes tested in Hamelmalo the number of clusters was increased to four, while the sub-clusters remained the same. This is due to genotype HD0134 which was outstanding in yield of Hamelamlo separated from cluster III and solely formed its own cluster (Cluster IV) (Figure 2). The general pattern of the structure in the two sites was similar, where genotypes collected from Gindae were inferred with genotypes from all the other sources (except NARI) into clusters I and II, while the majority of collections from Afabet inferred to cluster three along with genotypes from HAC and NARI. However, assignment of each genotype to specific clusters varied in the two sites indicating environmental factors had influenced the traits under study.

Table 2. Ranks of the best 14 collections based on yield, days to fruiting and three fruit quality parameters for dry consumed pepper in Eritrea. (Season 2013).

\begin{tabular}{|c|c|c|c|c|c|c|c|}
\hline Collection & $\mathrm{DFr}$ & $\mathrm{FL}(\mathrm{cm})$ & $\mathrm{FW}(\mathrm{cm})$ & FWTh (mm) & $\mathrm{Y} / \mathrm{Pl}$ (g) & $\begin{array}{l}\text { Selection } \\
\text { index }\end{array}$ & Rank \\
\hline HD0134 & 68.7 & 10.9 & 3.6 & 2.6 & 1139 & 4.2 & 1 \\
\hline HD0031 & 63.0 & 11.7 & 3.1 & 2.6 & 861 & 4.2 & 1 \\
\hline NRSG21 & 63.0 & 10.1 & 2.9 & 1.8 & 1110 & 3.8 & 2 \\
\hline NRSAF06 & 68.8 & 10.9 & 3.1 & 2.3 & 851 & 3.6 & 3 \\
\hline NRSAF09 & 65.5 & 11.5 & 3.1 & 2.3 & 559 & 3.4 & 4 \\
\hline NRSAF08 & 62.5 & 10.3 & 2.9 & 2.4 & 605 & 3.2 & 5 \\
\hline NRSAF12 & 66.0 & 10.5 & 3.1 & 2.3 & 602 & 3.2 & 5 \\
\hline HD0123 & 61.2 & 9.8 & 3.1 & 2.2 & 569 & 3.2 & 5 \\
\hline NRSAF07 & 68.2 & 10.7 & 3 & 2.3 & 540 & 3.2 & 5 \\
\hline NRSAF04 & 68.0 & 10.8 & 3 & 2.2 & 527 & 3.2 & 5 \\
\hline NRSAF02 & 69.3 & 10.7 & 2.8 & 2.4 & 607 & 3.0 & 6 \\
\hline HD0108 & 64.7 & 9.9 & 2.9 & 2.4 & 590 & 3.0 & 6 \\
\hline Red Long & 66.8 & 9.5 & 3.2 & 2.5 & 482 & 3.0 & 6 \\
\hline HD0128 & 58.8 & 9.5 & 2.6 & 2.1 & 433 & 3.0 & 6 \\
\hline
\end{tabular}


Plants respond morphologically to changes in their environment and cluster analysis has been used to group genotypes on the basis of response across environments [20]. In the current study clustering of the 60 genotypes using the combined data from the two experimental sites resulted in five main clusters at $85 \%$ coefficient of variation and 10 sub-clusters at $90 \%$ coefficient of variation. However, the structure was more realistic in grouping the genotypes based on seed source and elaborating the relationship among these groups.

Diversity studies on germplasm collected from gene-banks or farmers may include genotypes having different names for the same genotypes or genetically different materials having the same name [21] [22] indicating to duplication and narrow genetic diversity. However, studies on pepper landraces usually show high variability [17] [23]. In the current study, although the three clustering figures showed some genotypes to be closely related; however, no pairs or groups were observed to be identical indicating high variability among genotypes under study. Since the level of genetic diversity among cultivated crops depends on their reproductive behavior [24] and outcross levels in pepper ranges $0.5 \%$ to $92 \%$ [25] [26], this high variability is expected as a result of the nature of seed saving methods and growing in small adjacent plots adopted by pepper growers in Eritrea.

[27] found clustering of Spanish pepper based on their geographic origin. In contrast to that, many previous studies show, clustering of pepper genotypes was not according to geographic origin, justifying that by migration of materials that lead to gene flow between populations growing in different geographic regions [14] [28] [23]. However, in agreement with [17] the results of the current study showed clustering of genotypes was not completely influenced by geographic and agro-climatic factors. Genotypes collected from the same sub-region or institute tend to partially cluster together in large or small groups, but many genotypes clustered away from their group. Materials of Afabet, HAC and NARI are from three different agro-climatic regions and geographically distant from each other, but clustered together. Similarly, Gindae, Mendefera and Elabered are located in three different administrative and agro-ecological regions (Figure 1), however, seed obtained from Gindae was clustered with those obtained from Mendefera and Elabered. Seed exchange or common ancestry could be the best reason to explain the grouping of materials from the three sub-regions.

The seed exchange and common ancestry can better be elaborated by the total or partial clustering of materials from Afabet, HAC and NARI in the same group. In Afabet pepper is produced by small holding farmers in two villages (Naro-Ans and Kubkub) along the Mogae seasonal river. A distance of 8km separates the two villages. Land size allotted for pepper in the two villages ranges from $150 \mathrm{~m}^{2}$ up to a maximum of 2 ha [1]. Due to difficult access roads, the two villages are somewhat isolated from each other and more isolated from the other pepper production areas. Genotypes from HAC and NARI are breeding lines resulted from mass selection in two separate breeding programs. Seed from diverse local sources were used in the two breeding programs. Later NARI released some of its breeding lines to farmers. Therefore, either seed from NARI found its way to Afabet and crossed with other genotypes which some of it moved to HAC, or seed from Afabet found its way to the two breeding programs, suggesting a common ancestry and seed movement are the most probable reasons for clustering the three sub-populations together.

While cluster II in case of HAC and Cluster I in case of Asmara and combined data were a kind of admixture that included genotypes from almost all sources (Figures 2-4). Since Gindae and Mendefera are very old pepper producing areas, seed movement from the two places is widely known. Pepper farmers in Eritrea usually use their own seed that is passed from generation to the next, however, they also look for a reliable source of germplasm from other farmers within the village or farther places [1]. Therefore, the admixture cluster and individuals appeared away from their group possibly indicated that seed exchange has taken place among farmers from different areas [17] which is also a common practice in Eritrea, or it could be due to common origin or ancestry of the genotypes [29].

[24] [27] reported clustering of genotypes according to their fruit characteristics. Similarly [13] described fruit characters as the most influential variables in clustering results in studying pepper from Argentina. In the current study the results of the Principal Component analysis showed (data not shown) fruit traits are the major contributor to PC1, this could be one of the factors contributing to clustering of genotypes from Afabet, HAC and NARI together and Gindae, Mendefera, and the rest in different clusters. The reason is the pepper grown in Afabet and the breeding lines of NARI and HAC are for dry consumption, which is characterized by medium to long, wide with relatively thick pericarp fruits, while in the remaining regions growing for fresh consumption is more dominant. However, some farmers in later areas tend to grow varieties that serve both purposes. This gives rise to a third type which may explain clustering of some varieties from Afabet and HAC to cluster with collections from Gindae and the rest. Thus, the selection in each pepper growing area is influenced by the purpose of 
growing pepper being for fresh or dry consumption. However, the variability observed on different fruit traits indicates to intensity of selection for yield and fruit quality parameters. In similar study on pepper landraces of New Mexico pepper [9] described a long period of selection by farmers for various traits followed by adaptation to local conditions as a result of natural selection.

All genotypes except one in the list of best 14 genotypes for dry pepper (Table 2) are members of either Group IV or Group V; and only HD0128 belongs to Group I. This is confirmed by the average performance of the five groups for the 16 quantitative characters (Table 1). Based on the analysis of the combined data of the two sites, the result of the PCA (data not shown) showed that all the genotypes inferred to these two Groups had a high contribution to PC1 which is related to four yield contributing traits (Number of fruits/plant, fruit weight, fruit width and fruit wall thickness). Most genotypes in Group V and some Group IV also had medium to high contribution to PC2 which is related to yield/plant, plant height, stem thickness and fruit length. Except for fruit length and stem thickness, [15] reported all the previous traits to be correlated with yield. On the other hand, some of the genotypes in Group IV contributed highly to PC4 which is related to phonological traits, while all members of Group V had a high contribution to PC5 which is related to TSS and leaf characteristics. Thus, these two groups can be useful for selecting genotypes for improving yield and yield related fruit characteristics as well as earliness (Group IV) and TSS (Group IV). The contribution of the majority of genotypes inferred to Group II was basically to PC2 and PC4; but also a considerable number of genotypes in this Group had contributed to PC3 and PC5. [16] found a positive, non significant correlation between plant height and yield/plant, but the direct and indirect effect of plant height on yield was high. In studying Turkish red pepper, [30] suggested utilization of plant height for increasing yield/palnt. Similarly [31] reported indirect effect of plant height on yield. Although Group II was lower compared to Groups IV and V in the mean performance of the interrelated traits, plant height, stem thickness and fruit length, which are closely related to yield/plant. This could be due to differences in number of genotypes inferred to each cluster. Consequently, Group II may be useful as a source of genes for the aforementioned traits. Group I was mainly good contributor to PC3 which is related to cotyledon leaf length and width and days to germination; and PC5 which is related to TSS and leaf length and width. Thus, members of this Group can be useful as a source of individuals for selection or source of genes related to the aforementioned traits.

In Eritrea systematic introduction of improved varieties of pepper was absent for long periods and farmers continue to select and save their own seed [1]. This condition in addition to the nature of reproduction in pepper, seed saving in the absence of isolation techniques and other factors resulted in divergent gene pool that could be sufficient for supporting pepper improvement program. This is in contrast to [14] [24] who suggested the need for exotic germplasm for enriching the narrow gene pool of pepper in Ethiopia and Uganda respectively.

\section{Conclusion}

Most of the pepper germplasm in Eritrea is in the hand of farmers who traditionally save their own seed and path it from generation to the next. The results of the current study revealed the relatively high level diversity existed within the evaluated collections and partitioned them into meaningful groups. This information can be useful for initiating conservation strategy. It can also be useful for informed pepper breeding and improvement program. This study also identified at least four promising genotypes (HD0134, HD0031, NRSG21 and NRSAF06) for dry consumption. In addition to that, the study identified groups that can be used for selecting superior individuals or as a source of desired genes that are to be used in future peppers improvement programs such as cluster 1 for earliness in germination and high TSS and cluster 2 for taller plants. Finally the results confirm the diversity exists in Eritrean pepper sufficient for supporting pepper improvement program.

\section{Acknowledgements}

The authors express gratitude to the National Commission for Higher Education in Eritrea for funding the work and African Development Bank (ADB) as the original fund source. Deep gratitude also to the Hamelmalo Agricultural College (HAC) for providing experimental site, facilities and seed, Governor and staff of the Central Administration Zone for provision of experimental land and facilities (Asmara site), National Agricultural Research Institute (NARI) for conducting soil analysis and provision of seed, farmers in Eritrea for provision of seed used in this study and staff members of Institute for Biotechnology Research, JKUAT, Hamelmalo Agricultural College and Ministry of Agriculture, Eritrea for their support and contribution during the different stag- 
es of this work. Finally, special thanks to Mr. Semere Amlesom for his support efforts for securing experimental plots on both sites, Dr. Nasser Yao for his support and contribution to PCA and cluster analysis, Abdella Omer, Kiflom Tesfamichael and Abulrezak Hamde for their assistance in field work and data entry. Thanks also to VSN International Ltd. for providing free use of Genstat software.

\section{References}

[1] Saleh, B.K., Nyende, A.B., Kasili, R., Mamati, E. and Araia, W. (2013) Current Status and Future Opportunities of Pepper Production in Eritrea. ARPN Journal of Agricultural and Biological Science, 8, 655-672.

[2] Moscone, E., Scaldaferro, M.A., Grabiele, M., Cecchini, N.M., Garcia, Y.S., Jarret, R.L. and Ehrendorfer, F. (2007) The Evolution of Chili Peppers (Capsicum-Solanaceae): A Cytogenetic Perspective. Acta Horticulturae, 745, 137-170. http://dx.doi.org/10.17660/ActaHortic.2007.745.5

[3] Pickersgill, B. (1997) Genetic Resources and Breeding of Capsicum spp. Euphytica, 96, 129-133. http://dx.doi.org/10.1023/A:1002913228101

[4] Daskalov, S. (1986) Mutation Breeding in Pepper. FAO/IAEA, United Nations, Editors. Mutation Breeding Review, 4.

[5] Murillo-Amador, B., Rueda-Puente, E.O., Troyo-Diéguez, E., Córdoba-Matson, M.V., Hernández-Montiel, L.G. and Nieto-Garibay, A. (2015) Baseline Study of Morphometric Traits of Wild Capsicum annuum Growing near Two Biosphere Reserves in the Peninsula of Baja California for Future Conservation Management. BMC Plant Biology, $15,1$. http://dx.doi.org/10.1186/s12870-015-0505-6

[6] Mohammadi, S.A. and Prasanna, B.M. (2003) Review and Interpretation Analysis of Genetic Diversity in Crop Plants —Salient Statistical Tools. Crop Science, 43, 1235-1248. http://dx.doi.org/10.2135/cropsci2003.1235

[7] Roch, G., Bouchet, J.P., Sage-Palloix, A.M. and Daunay, M.C. (2010) Public and Commercial Collections of Heirloom Eggplant and Pepper: A Case study. In: Prohens, J. and Rodríguez-Burruezo, A., Eds., Advances in Genetics and Breeding of Capsicum and Eggplant, Proceedings of the XIVth EUCARPIA Meeting on Genetics and Breeding of Capsicum \& Eggplant, Valencia, 30 August-1 September 2010, 77-88.

[8] Franco, J., Crossa, J., Ribaut, J.M., Bertran, J., Warburton, M.L. and Khairallah, M. (2001) A Method for Combining Molecular Markers and Phenotypic Attributes for Classifying Plant Genotypes. Theoretical and Applied Genetics, 103, 944-952. http://dx.doi.org/10.1007/s001220100641

[9] Votava, E.J., Baral, J.B. and Bosland, P.W. (2005) Genetic Diversity of Chile (Capsicum annuum var. annuum L.) Landraces from Northern New Mexico, Colorado, and Mexico. Economic Botany, 59, 8-17. http://dx.doi.org/10.1663/0013-0001(2005)059[0008:GDOCCA]2.0.CO;2

[10] Govindaraj, M., Vetriventhan, M. and Srinivasan, M. (2015) Importance of Genetic Diversity Assessment in Crop Plants and Its Recent Advances: An Overview of Its Analytical Perspectives. Genetics Research International, 2015, Article ID: 431487. http://dx.doi.org/10.1155/2015/431487

[11] Peeters, J.P. and Martinelli, J.A. (1989) Hierarchical Cluster Analysis as a Tool to Manage Variation in Germplasm Collections. Theoretical and Applied Genetics, 78, 42-48. http://dx.doi.org/10.1007/BF00299751

[12] Bosland, P.W. (2010) An American in Spain. In: Prohens, J. and Rodríguez-Burruezo, A., Eds., Advances in Genetics and Breeding of Capsicum and Eggplant, Proceedings of the XIVth EUCARPIA Meeting on Genetics and Breeding of Capsicum \& Eggplant, Valencia, 30 August-1 September 2010, 21-25.

[13] Occhiuto, P.N., Peralta, I.E., Asprelli, P.D. and Galmarini, C.R. (2014) Characterization of Capsicum Germplasm Collected in Northwestern Argentina Based on Morphological and Quality Traits. AgriScientia, 31, 63-73.

[14] Nsabiyera, V., Ochwo-ssemakula, M.L.M., Sseruwagi, P., Gibson, P. and Ojiewo, C. (2013) Morphological Characterization of Local and Exotic Hot Pepper (Capsicum annuum L.) Collections in Uganda. Bioremediation, Biodiversity and Bioavailability, 7, 22-32.

[15] do Rêgo, E.R., do Rêgo, M.M., Cruz, C.D., Finger, F.L. and Casali, V.W.D. (2011) Phenotypic Diversity, Correlation and Importance of Variables for Fruit Quality and Yield Traits in Brazilian Peppers (Capsicum baccatum). Genetic Resources and Crop Evolution, 58, 909-918. http://dx.doi.org/10.1007/s10722-010-9628-7

[16] Yadeta, B., Belew, D., Gebreselassie, W. and Marame, F. (2011) Genetic Association among Some Attributes of Hot Pepper (Capsicum annuum L.) Genotypes in West Shoa, Ethiopia. Middle-East Journal of Scientific Research, 7, 567-573.

[17] Baral, J. and Bosland, P.W. (2002) Genetic Diversity of a Capsicum Germplas Collection from Nepal as Determined by Random Amplified Polymorphic DNA Markers. Journal of the American Society for Horticultural Science, 127, 316-324.

[18] IPGRI, AVRDC and CATIE (1995) Descriptors for Capsicum (Capsicum spp.). International Plant Genetic Resources Institute, Asian Vegetable Research and Development Center and Tropical Agricultural Research and Training Centre, 114. 
[19] Harding, S. and Payne, R. (2012) Multivariate Analysis, A Guide to Multivariate Analysis in GenStat ${ }^{\circledR}$. 15th Edition, VSN International, Hertfordshire, UK. http://www.genstat.co.uk/

[20] Schlichting, C.D. (1986) The Evolution of Phenotypic Plasticity in Plants. Annual Review of Ecology and Systematics, 17, 667-693. http://dx.doi.org/10.1146/annurev.es.17.110186.003315

[21] Hanáček, P., Cieslarová, J. and Stavělíková, H. (2009) DNA Polymorphism in Genetic Resources of Red Pepper Using Microsatellite Markers. Horticultural Science, 36, 127-132.

[22] Ghebreslassie, B.M., Githiri, S.M., Mehari, T. and Kasili, R.W. (2015) Analysis of Diversity among Potato Accessions Grown in Eritrea Using Single Linkage Clustering. American Journal of Plant Sciences, 6, 2122-2127. http://dx.doi.org/10.4236/ajps.2015.613213

[23] Fonseca, R.M., Lopes, R., Barros, W.S., Lopes, M.T.G. and Ferreira, F.M. (2008) Morphologic Characterization and Genetic Diversity of Capsicum chinense Jacq. Accessions along the Upper Rio Negro-Amazonas. Crop Breeding and Applied Biotechnology, 8, 187-194. http://dx.doi.org/10.12702/1984-7033.v08n03a02

[24] Geleta, L.F., Labuschagne, M.T. and Viljoen, C.D. (2005) Genetic Variability in Pepper (Capsicum annuum L.) Estimated by Morphological Data and Amplified Fragment Length Polymorphism Markers. Biodiversity and Conservation, 14, 2361-2375. http://dx.doi.org/10.1007/s10531-004-1669-9

[25] do Rêgo, E.R., Nascimento, M.F., do Nascimento, N.F.F., dos Santos, R.M.C., Fortunato, F.L.G. and do Rêgo, M.M. (2012) Testing Methods for Producing Self-Pollinated Fruits in Ornamental Peppers. Horticultura Brasileira, 30, 669672. http://dx.doi.org/10.1590/S0102-05362012000400017

[26] Bosland, P.W. (1996) Capsicums: Innovative Uses of an Ancient Crop. In: Janick, J., Ed., Progress in New Crops, ASHS Press, Arlington, 479-487.

[27] González-Pérez, S., Garcés-Claver, A., Mallor, C., de Miera, L.E.S., Fayos, O., Pomar, F., Silvar, C., et al. (2014) New Insights into Capsicum spp Relatedness and the Diversification Process of Capsicum annuum in Spain. PloS ONE, 9, e116276. http://dx.doi.org/10.1371/journal.pone.0116276

[28] Nicolaï, M., Cantet, M., Lefebvre, V., Sage-Palloix, A.M. and Palloix, A. (2013) Genotyping a Large Collection of Pepper (Capsicum spp.) with SSR Loci Brings New Evidence for the Wild Origin of Cultivated C. annuum and the Structuring of Genetic Diversity by Human Selection of Cultivar Types. Genetic Resources and Crop Evolution, 60, 2375-2390. http://dx.doi.org/10.1007/s10722-013-0006-0

[29] Naujeer, H.B. (2009) Morphological Diversity in Eggplant (Solanum melongena L.) Their Related Species and Wild Types Conserved at the National Gene Bank in Maauritius. International Masters Program at the Swedish Biodiversity Centre. Master's Thesis, Uppsala.

[30] Cankaya, S., Balkaya, A. and Karaagac, O. (2010) Canonical Correlation Analysis for the Determination of Relationships between Plant Characters and Yield Components in Red Pepper [Capsicum annuum L. var. conoides (Mill.) Irish] Genotypes. Spanish Journal of Agricultural Research, 8, 67-73. http://dx.doi.org/10.5424/sjar/2010081-1144

[31] Maga, T.J., Uguru, M.I. and Ogbonna, P.E. (2013) Variability and Association Studies on Yield and Yield Characters in Aromatic Nsukka Yellow Pepper (Capsicum annuum L.). International Journal of Plant Breeding, 7, 90-95. 